\title{
CONSTRUINDO NOVAS INTERAÇÕES: AVA E LOUSA DIGITAL INTERATIVA NO ENSINO SUPERIOR*
}

\author{
Elisa Netto Zanette \\ Universidade do Extremo Sul Catarinense - enz@unesc.net \\ Evânio Ramos Nicoleit \\ Universidade do Extremo Sul Catarinense - ern@unesc.net \\ Graziela Fátima Giacomazzo \\ Universidade do Extremo Sul Catarinense - gfg@unesc.net \\ Patricia Jantsch Fiuza \\ Universidade do Extremo Sul Catarinense - pjf@unesc.net \\ Cleusa Ribeiro dos Santos \\ Universidade do Extremo Sul Catarinense - csa@unesc.net
}

\begin{abstract}
Resumo: Resumo: Apresenta-se, neste artigo, o projeto piloto envolvendo o uso de lousas digitais interativas (LDI) por uma Instituição de Ensino Superior (IES) em disciplinas da graduação. As lousas digitais, no atual cenário pedagógico se consolidam, cada vez mais, como um recurso significativo no processo de ensino $e$ aprendizagem, ficando evidenciado na dinâmica das aulas, no resultado motivacional do acadêmico e nas atividades de aprendizagem. São discutidos os desafios e as possibilidades, a interação das lousas com o Ambiente Virtual de Aprendizagem (AVA), as competências técnicas e pedagógicas, a equipe envolvida, a formação dos docentes, os materiais digitais produzidos e os resultados do processo. Reflete-se ainda sobre o uso das tecnologias no ensino superior, sua incorporação nos espaços administrativos e pedagógicos, bem como as novas formas de ensinar e aprender mediadas pelas tecnologias. O projeto piloto resultou na implantação da metodologia e na ampliação do projeto em mais três unidades acadêmicas (UNA) na instituição.

Palavras-Chave: lousa digital, interatividade, ensino superior, educação a distância

\section{BUILDING NEW INTERACTIONS: VIRTUAL LEARNING ENVIRONMENT AND DIGITAL INTERACTIVE WHITEBOARDS IN HIGHER EDUCATION}

\begin{abstract}
This paper presents a pilot project involving the use of digital interactive whiteboards (LDI) in a Higher Education Institution (IES) in graduate programs courses. The digital whiteboards in the current pedagogical scenario consolidate, increasingly, as a significant resource in the teaching-learning process, becoming evident in the dynamics of classrooms, in the result of academic motivation and in the learning activities. It discusses the challenges and possibilities, the interaction of digital whiteboards with the Virtual Learning Environment (AVA), the required technical and pedagogical skills, the team involved, the experience of teachers, the digital material produced and the results of the process. It also reflects on the use of technology in
\end{abstract}

\footnotetext{
* Artigo aceito para apresentação no $16^{\circ}$ CIAED - Congresso Internacional ABED de Educação a Distância a ser realizado em Foz do Iguaçu/PR em setembro de 2010.
} 
Higher Education, its incorporation into teaching and administrative spaces, as well as new ways of teaching and learning mediated by technologies. The pilot project resulted in the methodology introduction and the project expansion into three academic units (UNA) in the institution.

Key-Words: digital interactive whiteboard, Interactivity, Higher Education, Distance Education.

\section{INTRODUÇÃO}

O avanço das Tecnologias de Informação e Comunicação (TIC) na última década tem influenciado de maneira direta o campo da educação. Nesse contexto, o atual perfil do aluno ingressante nos cursos superiores exige processos educacionais mais interativos, com uso de tecnologias que atendam a realidade social e ao mercado de trabalho, a fim de formar indivíduos com as competências necessárias para atuar na sociedade do conhecimento.

Neste cenário, a universidade se insere acompanhando a evolução da tecnologia e aprimorando o seu uso para fins educativos, apoiando os processos de aprendizagem dos alunos. Assim, relata-se a experiência de uma instituição de ensino superior na busca constante de inovação dos processos pedagógicos com a utilização de tecnologias digitais interativas, em específico, a lousa digital interativa (LDI), integrada ao Ambiente Virtual de Aprendizagem (AVA). Uma experiência que acena para a formação do docente, visando um novo olhar para o modo de ensinar e aprender.

\section{TECNOLOGIAS NO ENSINO SUPERIOR}

Adequar-se às inovações é relevante para acompanhar a evolução da tecnologia e da ciência em todos os setores da sociedade, em especial nas universidades, que são comprometidas em responder às demandas sociais de acordo com o momento histórico em que estão inseridas.

Inúmeras mudanças, ocorridas nos últimos anos, configuram o início de uma nova época que se caracteriza pela globalização e pelos avanços das tecnologias da informação e comunicação (TIC) evidenciando um novo contexto de mundo construído pela ação inteligente do homem, porém mais democrático, ou seja, que promova a participação e a emancipação do ser humano. Todas as transformações na teia de comunicações humanas refletem no campo da educação.

Quanto às tecnologias no ensino superior, há investimentos e mudanças por parte das universidades nos aspectos técnico-administrativos e nos aspectos pedagógicos. Com relação aos aspectos técnico-administrativos, a infraestrutura existente nas Instituições de Ensino Superior (IES) conta, na sua maioria, com o portal do campus para atender acadêmicos e docentes. Conforme dados de uma pesquisa realizada pelo CCR.BR (2008) em 132 instituições públicas e privadas do Brasil, 71,2\% possuem um portal institucional na web em funcionamento e 13,6\% em fase de implantação. Esses portais disponibilizam recursos para serviços de atendimento e apoio aos acadêmicos e docentes, bem como informações atualizadas e canais de comunicação com a instituição. Agrega-se a integração com os sistemas acadêmicos on-line, o diário eletrônico, a biblioteca, monitorias, os grupos de pesquisa, sistemas de avaliação institucional, dentre outros.

Entre as mudanças inseridas nos processos pedagógicos, citam-se como exemplos de tecnologia a internet, o projetor multimídia, recursos de Educação a Distância (EaD) e com esta modalidade o uso de AVA, softwares e ferramentas de interação on-line e off-line, a Web 2.0, sistemas de audioconferência, videoconferência 
e webconferência, videoaulas, conteúdos digitais, objetos de aprendizagem, comunidades virtuais, redes sociais, Lousas Digitais Interativas (LDI), dentre outros.

Uma Lousa Digital Interativa (LDI) é tipicamente equipada com várias ferramentas para auxiliar o professor na sua ação educativa. É um recurso que possibilita o acesso a materiais pré-organizados e à internet. Por meio da LDI é possível ainda interagir com arquivos multimídia, salvar anotações feitas durante uma aula e até promover atividades com a participação dos alunos em grupos ou individualmente.

Os materiais, para uso em uma LDI, requerem preparo prévio e disponibilidade dos professores, além de capacitação técnica e pedagógica específica para o uso adequado dos equipamentos e softwares.

A LDI é apresentada por Nakashima, Barros e Amaral (2009) como um recurso de mediação entre as atividades propostas pelo professor e a compreensão e a assimilação das mesmas pelos alunos, auxiliando no desenvolvimento de práticas inovadoras de ensino e de aprendizagem. Essas atividades elaboradas na lousa digital são mais flexíveis, possibilitam atualização constante das informações, além de possibilitarem o uso de softwares de simulação. "Dessa forma, o conteúdo desenvolvido em uma aula pode ser salvo pelo professor, transformando-o em um arquivo que poderá ser utilizado novamente em outra aula.” (NAKASHIMA, 2008).

Destaca-se que a simples utilização de tecnologias não garante mudanças nos processos de ensino e de aprendizagem. De acordo com Borba; Moraes e Silveira (2005, p. 130):

\begin{abstract}
Faz-se necessária uma apropriação das mesmas, o que significa não apenas adaptá-las a abordagens tradicionais de ensino: utilizá-las como ferramenta para transmitir informações significa subutilizar tais tecnologias. É necessário que estas sejam vistas como ferramentas cognitivas que propiciam trocas, interação, cooperação entre os pares, pesquisa, seleção, avaliação, trabalho em grupo, questionamentos, habilidades necessárias para a sociedade do conhecimento em que se vive hoje.
\end{abstract}

O cenário apresentado exige cada vez mais discussões sobre a definição de políticas e planejamento envolvendo Tecnologias de Informação (TI) nas IES. O potencial revolucionário das tecnologias indica a necessidade das instituições, devido a constantes mudanças, formarem equipes multidisciplinares preparadas para avaliar, experimentar e propor estratégias de uso dessas novas tecnologias no ensino superior. A EaD já indicava esta necessidade, visto que as IES criaram setores e núcleos para desenvolver esta modalidade de ensino.

A universidade em sua função básica de produzir e disseminar conhecimentos se apresenta com novos desafios associados ao advento da internet e da modalidade de EaD. No Brasil, as influências da EaD e dos avanços das TIC se tornam cada vez mais evidentes em todas as áreas: acadêmicas, empresariais e tecnológicas.

\title{
3 EXPERIÊNCIA NO USO DAS LOUSAS DIGITAIS INTERATIVAS
}

Os debates acerca de práticas pedagógicas com inovações tecnológicas nos cursos de graduação da Unesc ocorrem, há vários anos, a partir de políticas institucionais de fomento à cultura de EaD na IES e de pesquisas e estudos permanentes para o planejamento e desenvolvimento de ferramentas para o AVA. Essas ações se mostraram mais efetivas nos últimos anos com a maior adesão de docentes e discentes no uso do AVA, processo que se potencializou com a sua integração ao Sistema Acadêmico da Universidade e a implantação do diário de classe on-line.

Os envolvidos no projeto piloto das LDI integram profissionais do Setor de Educação a Distância (SEAD), do Departamento de Tecnologia da Informação (DTI) e docentes da Unidade Acadêmica de Ciências, Engenharias e Tecnologias (UNACET). 
O projeto de implantação de LDI na Unesc iniciou em forma gradativa por meio de uma proposta de projeto experimental, ao final de 2008. Os objetivos iniciais foram: desenvolver um projeto experimental com a integração das LDI na prática docente que possibilitasse a produção e a autoria do material digital pelo docente no seu planejamento diário e; prover o docente e o discente de recursos interativos que possibilitassem aulas dinâmicas e adequadas ao perfil do acadêmico deste milênio, usuário freqüente e simpatizante de TIC.

A proposta possibilitou ao professor transferir o desenvolvimento de ações no quadro convencional para a LDI e ao final da aula ou atividades, salvar o seu trabalho em formato digital e publicá-lo na sala virtual. Assim, as aulas ficam publicadas na versão textual no AVA com acesso a qualquer momento pelos acadêmicos.

Participaram do projeto, que foi implantado no $1^{\circ}$ semestre de 2009, sete (07) professores e trezentos (300) acadêmicos de sete (07) disciplinas de três (03) cursos de graduação da UNACET (Engenharia Química, Engenharia Ambiental e Engenharia de Materiais). Um dos critérios de seleção de professores para participar do projeto era a comprovada experiência dos docentes no uso dos recursos do AVA e o interesse em investigar práticas pedagógicas aliadas ao uso das tecnologias.

$\mathrm{Na}$ primeira reunião com os docentes envolvidos no projeto, os integrantes acordaram alguns procedimentos para o sucesso do projeto. Os docentes foram capacitados para utilizar a LDI e assim, convidados a explorar o maior número possível de recursos. Durante o semestre, os docentes foram convidados para participar de mais duas reuniões com os integrantes do projeto para socializar as experiências, as limitações e as possibilidades de usos da LDI e para debater sobre as questões relacionadas à logística de uso da sala, entre outras. Surgiram depoimentos dos docentes sobre: entusiasmo dos acadêmicos com a facilidade de acesso às atividades publicadas no AVA; interação dos acadêmicos no desenvolvimento de atividades por meio da LDI; dificuldades (do acadêmico e do docente) de adaptação inicial em relação ao quadro convencional; logística de acesso à caneta da lousa; inadequação da sala de aula para as turmas maiores; dentre outros. Estas ocorrências evidenciaram-se, principalmente nas disciplinas que exigem processos longos de análise e conclusão dos problemas;

Ao final do semestre o projeto foi avaliado com docentes e discentes. Os métodos e resultados desse processo serão detalhados a seguir.

\section{RESULTADOS DO PROJETO PILOTO :}

Para a execução do projeto piloto experimental, foi utilizada uma sala de aula equipada com uma (01) LDI, um (01) computador com acesso à internet e um (01) projetor multimídia. A logística de uso da sala foi organizada por dia/turma/docente.

\subsection{Análise dos Resultados da Pesquisa com Docentes}

Apresentam-se os resultados da avaliação realizada com os sete (07) docentes. Utilizou-se instrumento de avaliação quantitativa com 12 questões fechadas e uma questão aberta, aplicado no final do semestre 2009/1. O mesmo objetivou analisar com os docentes as potencialidades e limitações no uso pedagógico da LDI.

Com relação à infraestrutura da sala e adequação desta para o uso da LDI, 71\% responderam sim, 14\% parcialmente e 14\% não. Sobre isto, é importante entender que muitas foram as alterações durante a execução do projeto para adaptar o ambiente incluindo: projetor multimídia compatível, monitor de vídeo, logística de uso da caneta, instalação de suporte para canetas e outros que se fizeram necessários. Destaca-se que o layout da sala deve favorecer o docente para o uso da LDI de forma ágil. As dificuldades se relacionam, por exemplo, com a projeção e incidência da luz sobre a 
lousa. Isto demanda testes para verificação da melhor distância entre os equipamentos, evitando-se assim sombras e reflexos. Seguem as sugestões dos docentes sobre infra-estrutura: a) aproximar o mouse e o teclado da lousa; b) revisar e adequar a logística e o suporte da caneta; c) a sala, para turmas com 54 alunos, deve ser maior. Quanto às ações didáticas mais utilizadas com a LDI, os resultados foram: escrever sobre o quadro branco do bloco de notas - 86\% sempre; navegar no editor de apresentação, editor de textos ou PDF - 43\% sempre e $43 \%$ às vezes; acessar a sala virtual no AVA - 86\% sempre; desenvolver conteúdo da disciplina - 86\% sempre; publicar o conteúdo desenvolvido na sala virtual - 71\% sempre; gravação da aula - $43 \%$ sempre e $43 \%$ nunca.

As ações didáticas referem-se a interação entre os conteúdos, o docente e os acadêmicos por meio da LDI. O nível de interação é determinado pelo planejamento da aula, ou seja, numa aula altamente planejada, onde inserem-se objetos, simuladores, problemas e/ou expressões matemáticas previamente organizadas, agiliza-se e há um ganho de tempo para docentes e acadêmicos focarem em dúvidas e questionamentos. Neste caso, constata-se que os docentes, na sua maioria, usaram o quadro branco do bloco de notas para desenvolver e registrar a abordagem dos conteúdos desenvolvidos em aula e publicá-los no AVA. Esta ação colabora para os acadêmicos revisarem posteriormente os conteúdos; acompanhar as aulas a distância e/ou na impossibilidade de participar no presencial; serve também como ponto de retomada para a próxima aula pelo docente, em especial nas disciplinas da área das exatas onde o desenvolvimento de cálculos é sempre solicitado. Com isto, se pode ir construindo de forma processual significativo o conteúdo digital da disciplina durante as aulas, otimizando o tempo. São estas as "novas interações" que destacam-se neste artigo, para que o uso das LDI não se torne apenas um instrumento mais sofisticado para uso de apresentações em projetores multimídia.

Com relação aos recursos da barra de ferramentas, as mais utilizadas foram: holofote, captura de tela, revelar, recorte de tela, plano de fundo e em menor menção: realce de texto, colar figura e inserir texto. Os recursos são utilizados de acordo com a necessidade e por isso as opções mudam entre os docentes, mas todos apresentam boas possibilidades pedagógicas. Neste caso, a captura de tela com $57 \%$, foi a mais citada.

Ao perguntar qual o recurso gostaria de usar e não encontrou na lousa digital, dois (2) docentes responderam que não encontraram: a) uma borracha na barra superior de trabalho, sem precisar abrir a caixa de ferramentas; b) como gravar áudio; c) como publicar automaticamente no AVA.

Sobre a publicação, a LDI salva em arquivo em formato próprio ou gera um arquivo em formato pdf a partir do documento, opção mais utilizada para publicar no AVA. Quando perguntados se os acadêmicos interagiram com a LDI durante as aulas, as opções sempre e às vezes somam $86 \%$, indicando que é possível aproveitar as contribuições dos acadêmicos na condução das aulas e nos materiais de aula produzidos e, por outro lado, incentivando a participação deles.

O software da LDI pode ser disponibilizado aos docentes em seus computadores pessoais. Assim, podem-se preparar previamente os materiais digitais que serão usados na aula. Quando perguntados se planejam as aulas previamente no software da LDI, $49 \%$ responderam sempre, $29 \%$ às vezes e $29 \%$ nunca. Esse recurso é uma opção adicional para o docente utilizar ou não. Constata-se um equilíbrio entre os que adotam e os que não adotam esta prática. É preciso considerar o tempo de uso da LDI desses docentes. Mesmo assim, entende-se que é fundamental a disponibilizacão dos softwares das LDI, pois os mesmos são importante para a capacitação, familiarização do recurso e planejamento prévio das aulas. 
Sobre a familiarização do recurso e uso da LDI, 86\% afirmam não terem dificuldades e $14 \%$ responderam que sim. A análise indica que docentes com maior dificuldade com o uso de outros recursos e ou que ainda não usavam o AVA na sua prática docente encontraram mais dificuldades.

\subsection{Análise dos Resultados da Pesquisa com Discentes}

O instrumento de pesquisa aplicado aos acadêmicos foi estruturado em forma de um questionário com 10 perguntas, disponibilizado com o uso da ferramenta QUIZ no AVA. Foi disponibilizado também, um fórum virtual para sugestões e relato da experiência de uso da LDI. Os acadêmicos convidados a participar da avaliação do projeto foram trezentos (300), sendo que destes, oitenta (80) acadêmicos (26,7\%) participaram por adesão da avaliação.

Sobre os recursos da LDI utilizados pelo docente na disciplina, o mais citado por 58 acadêmicos (72,5\%), foi escrever no quadro branco da LDI seguido de publicar o conteúdo desenvolvido na sala virtual; acessar a sala virtual; navegar no editor de apresentação, editor de textos e em arquivos de extensão PDF; internet e outros softwares.

Os acadêmicos foram convidados a citar quais recursos gostariam que o docente utilizasse na LDI para melhorar as atividades de aula. O recurso mais citado foi a publicação das atividades desenvolvidas no quadro branco da lousa no AVA (65\%); $53,7 \%$ citaram o uso do quadro branco da lousa para desenvolver atividades; 48,5\% citaram o uso dos recursos da Internet nas aulas; 43,7\% sugerem o uso de materiais em editores de texto, editores de apresentações ou PDF; 42,5\% o acesso ao AVA durante as aulas e $31,2 \%$ o uso de outros softwares aliados ao recurso da lousa digital. Constata-se que a publicação das atividades desenvolvidas em sala de aula no AVA predomina como fator importante para o acadêmico. No fórum virtual os acadêmicos responderam quanto à participação na experiência de ter aulas com o recurso da LDI e com relação às melhorias de uso da mesma. Entre os comentários destacam-se:

"A lousa no começo era mais demorada do que o quadro antigo. Depois nós vimos as facilidades que ela proporciona como ter oportunidade de não precisar anotar e poder pegar as explicação no AVA”.

Evidenciou-se nos depoimentos que a atenção ficou concentrada nas atividades de aula, nas discussões, na apresentação das informações pelo docente e pelos colegas. Como cita outro acadêmico no fórum:

"A utilização da lousa durante as aulas foi muito boa para a nossa aprendizagem. Ela deixa as aulas mais ágeis e eficientes. Pois, com ela não precisamos copiar todos os exercícios devido ao fato de podermos acessá-los em casa, tendo assim, maior tempo para os professores explicarem o conteúdo..."

O processo de formação docente no uso de tecnologias tem mostrado que o uso do recurso nem sempre é simples e de fácil apropriação. Dominar a tecnologia não significa, necessariamente, domínio pedagógico da mesma. Além disso, alguns docentes, diferente dos discentes, que são nativos digitais, demoram mais na apropriação dos novos recursos.

"Gostei da lousa, mas algumas vezes a Profa e os alunos se complicavam para utilizar as ferramentas de escrita, retas (vetores), plano cartesiano. Porém, acho que com um pouco mais de familiarização a lousa será um recurso muito mais rápido e interessante e pode ser adaptado para cada pessoa.”. 
Com relação ao uso em outras disciplinas, um acadêmico confirma essa importância afirmando:

"Gostei bastante de ter aula com essa nova ferramenta, aconselho colocar em outras disciplinas."

\section{CONSIDERAÇÕES}

Com este projeto piloto foi possível constatar a importância das IES estarem constantemente inovando os processos pedagógicos com o uso de tecnologias interativas, em específico as LDI. Este movimento na universidade implica num trabalho integrado entre diversos segmentos e profissionais de diferentes áreas do conhecimento, possibilitando agregar conhecimento técnico, pedagógico e formação docente. É importante destacar que essa iniciativa relaciona-se fortemente com o trabalho do Setor de Educação a Distância da IES, responsável pelo fomento e acompanhamento da utilização das tecnologias na educação e em especial do uso do AVA.

Fica fortemente evidenciado o avanço qualitativo do trabalho docente no seu fazer pedagógico, desde o planejamento, os procedimentos adotados, a socialização das experiências e a organização dos materiais e conteúdos para o uso da LDI. Neste caso, agregou-se o uso do AVA para disponibilização de materiais digitais numa proposta de ensino interativo, num processo que possibilita a autoria docente.

As análises mostram o envolvimento dos docentes e suas respectivas ações didáticas mais utilizadas com a LDI, a reflexão sobre esse fazer, as aulas altamente planejadas e o uso de diferentes softwares que possibilitaram uma maior agilidade e ganho de tempo para que o foco fosse a aprendizagem sobre os acadêmicos no momento da aula. Quanto aos acadêmicos, os ganhos relacionam-se com ampliação dos conteúdos ministrados, a revisão posterior dos conteúdos, o acompanhamento das aulas a distância e a retomada dos conteúdos num processo de aprendizagem contínuo.

Como indicadores de prospecção tem-se uma ampliação do uso das LDI integrado ao AVA, produção de material didático digital em tempo real, formação avançada técnica e pedagógica do docente e expansão dos projetos integrados entre DTI, UMA e setores e cursos da IES.

Registra-se ainda que o projeto piloto resultou na implantação da metodologia e ampliação do projeto em mais três unidades acadêmicas na instituição em 2009/2010, com a aquisição lousas adicionais e planejamento de expansão.

\section{REFERÊNCIAS}

BORBA, Márcia de C.; MORAES, Márcia C.; SILVEIRA, Milene S. Recursos tecnológicos na ação docente. In: ENRICONE, Délcia; GRILLO, Marlene. Educação Superior: vivências e visão de futuro. Porto Alegre: Edipucrs, 2005.

CCR.BR - Campus Computing.Br: a computação e tecnologia da informaçã nas instituições de ensino superior no Brasil/organização Associação Brasileira de Educação a Distância. São Paulo: Pearson Prentice Hall, 2010.

NAKASHIMA, Rosária Helena Ruiz. Sistematização de indicadores didático-pedagógicos da Linguagem interativa da lousa digital. Disponibilizado em:

http://www.pucpr.br/eventos/educere/educere2008/anais/pdf/521_204.pdf (2008). Acesso em 12 de abr.2010.

NAKASHIMA, Rosária Helena Ruiz; BARROS, Daniela Melaré Vieira; AMARAL, Sergio Ferreira do. $\mathrm{O}$ uso pedagógico da lousa digital associado à teoria dos estilos de aprendizagem. Disponível em: 
http://www.uned.es/revistaestilosdeaprendizaje/numero_4/Artigos/lsr_4_articulo_12.pdf (2009). Acesso em 15 de abr.2010. 